\title{
Time as a Network Good: Evidence from Unemployment and the Standard Workweek
}

\author{
Cristobal Young, ${ }^{\text {C Chaeyoon Lim }}{ }^{\mathrm{b}}$
}

a) Stanford University; b) University of Wisconsin-Madison

Abstract: We argue that time is a network good: its value depends on the number of social others who have the same schedule of time available. We demonstrate this in a comparative analysis of how the standard workweek shapes the social time and emotional well-being of workers and the unemployed. Drawing on two independent data sets, with more than half a million respondents, we show that both workers and the unemployed experience remarkably similar increases in emotional well-being on weekends and have similar declines in well-being when the workweek begins. The unemployed look forward to weekends much the same as workers. This is in large part because social time increases sharply on weekends for both workers and the unemployed. Weekend well-being is not due to time off work per se but rather is a collectively produced social good stemming from widely shared free time on weekends. The unemployed gain comparatively little benefit from their time off during the week, when others go to work.

Keywords: unemployment; time use; workweek; network goods; well-being

Editor(s): Stephen L. Morgan; Received: October 16, 2013; Accepted: October 24, 2013; Published: February 18, 2014

Citation: Young, Cristobal, and Chaeyoon Lim. 2014. "Time as a Network Good: Evidence from Unemployment and the Standard Workweek." Sociological Science 1: 10-27. DOI: 10.15195/v1.a2

Copyright: (C) 2014 Young and Lim. This open-access article has been published and distributed under a Creative Commons Attribution License, which allows unrestricted use, distribution and reproduction, in any form, as long as the original author and source have been credited.

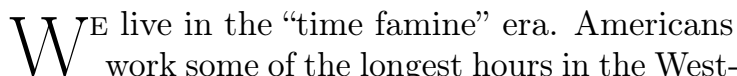
ern world, with the added challenge of women working "second shifts" in the home and growing expectations of men both to work and be active in the domestic sphere (Hochschild 1997; Williams 2010; Verbakel and DiPrete 2008). As a result, many Americans feel that there is not enough "time for life" (Robinson and Godbey 2000; Bianchi, Robinson, and Milkie 2007; Jacobs and Gerson 2004; Lyness et al. 2012; Hochschild 1997; Schor 1991; Evans, Kunda and Barley 2004). However, extra free time per se may be a very limited solution to these challenges.

Time is often conceived in terms of quantity, in which the principal problem is one of shortage: there are simply not enough hours in the day. We argue, in contrast, that time is a network good (DiMaggio and Garip 2011, 2012; DiMaggio and Cohen 2005). The value of time depends in part on an individual's ability to coordinate that time with others (Winship 2009; Bittman 2005; Zerubavel 1981, 1985). As such, concerns about time are a coordination problem as well as a quantity problem. This study examines the value of time for people who gain extra hours that are at odds with social coordination. We compare workers and the unemployed as they cycle through day-by-day changes in the amount of free time available to them that is either shared with others or spent privately.

During recessions, when unemployment is rising, there is a growing time inequality between workers living in a time famine world and the unemployed with plenty of time to spare. Recessions increase the aggregate hours of free time that people have available, but those hours are heavily concentrated among a relatively small segment of the population. The concentration of recessionary free time is not obviously problematic from the perspective of time as a valuable commodity. Despite the hardships of job loss (Young 2012; Newman 1999; Burgard, Brand, and House 2007), the unemployed gain about 35 hours a week that no longer belong to an employer. A central assumption of labor economics is that "utility depends negatively on hours of work" (Keane 2011:966) — the classic labor-leisure trade-off. Casual observers sometimes wonder if the jobless are enjoying their free time too much, undercutting their desire to find new work. The Unemployment Insurance program is often crit- 
icized as providing a "subsidy" for "leisure" by "paying people not to work" (e.g., Feldstein and Altman 2007:40; Levin and Wright 2001:375; see also Keane 2011; Krueger and Meyer 2002; Blundell and MaCurdy 1999). Critics described the extended Unemployment Insurance benefits during the Great Recession as turning "our social safety net into a hammock" (Weiner 2011:1).

If time is simply a valuable commodity, there is a clear upside to unemployment. The free time that unemployment creates could be compared to an extended weekend. For most people, the weekend represents "two days of freedom" (Rybczynski 1991:7) in which workers live by their own schedules, do what they choose, and spend time with whom they want-rather than living by the demands of their jobs. It seems to follow naturally, then, that more days off offer more freedom, more happiness, and more personal fulfillment.

From the perspective of a network good, however, the essential characteristic of the weekend is not just the having of a day off but rather that other people have the day off. The standard workweek serves as a coordinating mechanism, ensuring that time off work can be converted into social time. The opportunity cost of working depends on the hours that other people work. The freedom of the weekend stems in large part from the availability of others.

This study addresses two interrelated questions:

1. To what extent is time a network good? How much does the availability of others shape and determine the value of time?

2. How much of the enjoyment of weekends is due simply to having a day off workreducing time pressure and avoiding the disutility of paid labor? How much of the enjoyment of the weekend can be gained by not working on weekdays?

We use the unemployed as a strategic case to answer these questions. We factor out the net cost/distress of unemployment and focus on difference-in-difference comparisons of workers and the unemployed by day of week: the difference in how each group experiences Monday to Friday compared to Saturday and Sunday.
Drawing on half a million respondents from the Gallup Daily Poll, we show that there are striking similarities in day-to-day patterns in the emotional well-being of workers and the unemployed. Both experience a clear spike in their well-being on weekends and a drop in well-being during the week. Specifically, the unemployed experience about 75 percent of the subjective benefits of weekends: not going to work during the week gives the jobless roughly 25 percent of the weekend experience (in terms of day-of-week well-being). To much the same degree as working people, the unemployed are "living for the weekend." This suggests that what people value most about weekends is not the day off work per se but the social opportunities that are possible on widely shared days off.

We calibrate this finding by testing for similar patterns in social time with family and friends using eight waves of the American Time Use Survey (ATUS). Social time - for both workers and the unemployed - increases notably on weekends and drops during the week. These differences in social time explain roughly half of the weekend effect in well-being. In other words, roughly half of the reason why people enjoy weekends is the opportunity to spend more hours with family and friends, which is true for both workers and the unemployed. The remaining, residual benefit of the weekend is not empirically accounted for but accrues similarly among the unemployed and workers and may be due to differences in the quality, as well as quantity, of social time on weekends.

The comparative dynamics of free time among workers and the unemployed sheds unique light on underappreciated social facts: the network properties of time, the role that an institutionalized standard workweek serves in facilitating social time, and the difficulties of resolving time pressure through private individual action without broader social coordination.

\section{Scheduling Constraints and the Marginal Value of Time}

Time, as Winship (2009) observed, comes with two basic kinds of limitations: the budget constraint and the scheduling constraint. The chal- 
lenge of the budget constraint is simple: there are only 24 hours in a day. In this simple model, time is a homogeneous quantity: an hour is an hour, and the main problem is that there are not enough hours in a day.

The scheduling constraint, however, shapes what individuals can do with their endowment of time. It reflects an individual's ability to coordinate time and place with the people with whom the individual wants to interact and limits how an individual can transform free time into valued social time. Budget constraints are obviously important, but often people's real frustrations with time are due to the scheduling constraint - the challenge of aligning available time with that of others.

Often, people's desire for more time is really a desire for better temporal scheduling that allows more joint activity with other people (and their schedules). Increasing one's budget of free time (say, by working less) is at best a partial solution because working less does not change other people's schedules.

In this sense, time is not like money but more like goods in a barter economy. Barter requires what Jevons (1890) called a "double coincidence of wants" (pp. 3-4): for exchange to occur, each party needs to have specific goods that the other party specifically wants (cf. Stovel and Fountain 2009). If a farmer wishes to build a house, the farmer must find someone who both (1) wants the farmer's produce and (2) has lumber or building supplies to exchange. Without a generalized currency, it is difficult to find exchange partners, and the farmer's produce has limited value.

Time suffers from a similar lack of fungibility (Winship 2009:502; Leclerc, Schmitt, and Dube 1995). Time cannot be traded or exchanged directly. A surplus of time cannot be stored away and used later; it can only be consumed in the moment, whether it is particularly wanted or not 1 In contrast to money, time is a perishable $\operatorname{good}{ }^{2}$

This means that unexpected time savings, rather than being a windfall gain, often leads to using time in ways that have low marginal value

\footnotetext{
${ }^{1}$ In this sense, a surplus of free time is rather like being paid in hamburgers: its value depends on how many hamburgers you can enjoyably eat in one sitting.

${ }^{2}$ In a hyperinflation economy, money and time become much more similar currencies.
}

to individuals 3 Time slots increase in value when they can be shared with more people. For time to have a high marginal value, it often requires a double coincidence of wants - one or more social others (spouse, friend, family member) who have the same schedule of free time. Otherwise, free time becomes spare time, and individuals face the prospect of "bowling alone" (Putnam 2000).

\section{Time as a Network Good}

Network goods are things that increase in value as more and more people have them: whenever someone new acquires the good, it creates a positive externality for others. The telephone is a classic example. In 1910, few people had telephones in their homes. As a result, there was little reason for a person to own a phone: there was no one to call. As the network of phone ownership expanded, there was more and more reason to invest in one. Every new household and business that had a phone created an incremental benefit to telephone ownership in general, as the technology increased in utility. Virtually all information technologies have these kinds of network effects: the value of e-mail, Facebook, Craigslist, PayPal, and text messaging all depend on how many other users there are (and often on how many users a person knows) (DiMaggio and Garip 2012; DiMaggio and Cohen 2005; Shapiro and Varian 1999). Things like dating or carpooling likewise depend on how many other people want to do them; neither activity is possible without other available participants. When one person becomes single again, it creates a positive externality for other single people (Åberg 2009).

Time is a quintessential network good. Few things are best done alone. Most activities are either more enjoyable or more productive when done with others. The efficacy of things like factory production, political protests, church gatherings, Christmas parties, family dinners, and football games depends on how many people show up for them. When an additional person goes to church, that person creates a positive exter-

\footnotetext{
3 The idea of "saving time" suggests a continuous schedule of activities, so that when one task is completed more quickly, an individual can start the next task ahead of schedule. The opposite of this is the "hurry up and wait" problem: the next task requires input from others who are not ready ahead of schedule.
} 
nality for other churchgoers, who can enjoy a more vibrant religious experience. The more family members show up for Thanksgiving dinner, the more a sense of family is created. Of course, network goods can run into diminishing returns and congestion problems. Production-line factory systems cannot run if only a few workers show up, but there can also be too many workers. Likewise, dinner parties can be too big, and there can be too many cooks in the kitchen. Infinitely increasing returns to a population are not needed for network effects to be important. For many leisure activities, a handful of people make the difference between isolation and rich interaction. In any event, coordinating multiple participants to be engaged in the same social event is a basic precondition for successful "interaction rituals" that generate the emotional energy, mutual entrainment, collective effervescence, and feelings of solidarity and belonging that make up the microfoundations of society (Collins 2004).

\section{The Standard Workweek as a Coordinating Mechanism}

The standard workweek is one of the most important (and taken-for-granted) institutions to provide social coordination of time and participation. By coordinating people to work much the same hours and take the same days off, the standard workweek makes both work and leisure more attractive (so long as they happen at the right times). First, a standardized workweek means that when a person has a day off work, so do most other people that individual knows. This maximizes shared time available for social interaction on days off (weekends and holidays) and raises the value of leisure time for most people. Second, when the individual has to go to work, so does most everyone else. The standard workweek reduces the opportunity cost of going to work; there are few important events that people are missing during usual working hours. This limits the desire to take extra time off and encourages full-time work.

In contrast to a standardized workweek, imagine a system in which there are no fixed weekends; all days are potential workdays (Hornstein 2002). People choose which two days they want to take off. People work five out of seven days, and each day, roughly five-sevenths of the labor force comes into work. Factories and office buildings run with a mostly full (70 percent) staff seven days a week. Because people would have greater choice over their working days, the system offers a net increase in freedom. It is analogous to ending the custom of church on Sundays and letting churchgoers of each congregation sort out for themselves which day would really work best for worship.

A rotating, seven-day workweek is not just a thought experiment. It was implemented on a mass scale in the Soviet Union in 1929, in an effort to maximize industrial production (Zerubavel 1985; Foss 2004). The central goal was to keep the factories running every day, transforming the 52 Sunday shutdowns per year into full production days. The new "Red Calendar" was a complex creation that divided the months into five-day, rather than seven-day, weeks. Factories would operate every day, with 80 percent of staff on duty. Each day, one-fifth of workers would have the day off. The new calendar allowed for the continuous operation of factories and also increased the number of leisure days workers had. Soviet workers now rested one out of every five days (73 days a year) rather than the previous one out of seven (52 days a year) (as was the norm in the West at that time). In effect, the new system increased the workweek of capital, while reducing the workweek of labor. Nonetheless, the Red Calendar survived only two years and suffered many practical problems of implementation. Most importantly, as Foss (2004) notes, "workers hated it" (p. 47).

The Red Calendar gave people more free time but made it exceedingly difficult to coordinate that time with anyone else. Many families saw their shared rest day - the old Sunday — disappear. They now had more days off, but many never had the same day off as their spouse. "Authorities essentially divided the entire society into five separate working populations, staggered vis-a-vis one another" (Zerubavel 1985:38). If spouses were assigned different workdays, they would almost never have a shared day of rest. Only 20 percent of the workforce would share a common rest day, so the odds of connecting with family and friends were low. "In address books, people would add to the names of friends and acquaintances ... the day of the week on which [those people] were off duty" (Zerubavel 1985:37). The official Soviet 
newspaper Pravda gave voice to the complaint: "What is there for us to do at home if our wives are in the factory, our children at school, and nobody can visit us . . . ? It is no holiday if you have to have it alone" (quoted in Zerubavel 1985:38; emphasis added).

The central lesson from this experiment in reengineering time is the primacy of scheduling constraints and the network properties of free time. Even large increases in the budget of free time matter little when those hours are disconnected from the lives of our social others. We do not just want time away from work; we want free time when our family and friends have free time.

A modest formalization helps to drive this point home. In a society without a standard workweek, the chance that a rest day, $r$, can be jointly shared with $n$ people is proportional to $r^{n}$. The coordination challenge increases exponentially with the number of people involved. With two rest days per seven-day week, each person has an $r=0.28$ chance of being off work on a given day. What are the chances that their days off by coincidence align with others? For two friends (i.e., $0.28^{2}$ ), the daily chance that they will have the same day off is only 8 percent (once every 12 days), for three friends the chances are a mere 2 percent (once every 45 days), and for four friends the chances are roughly one-half of 1 percent (once every 162 days). The occasion of four specific people having the same day off work purely by chance would happen only twice a year. Without the coordination of a standardized workweek, friends and family members would rarely have the same day off work.

\section{Weekend Effects}

What is a weekend? Is it just two days when one does not have to go to work? Is the weekend primarily about avoiding the disutility or unpleasantness of work? If so, workers could privately re-create their experience of the weekend anytime they choose by taking extra days off. We argue that the essence of the weekend is not the avoidance of work per se but rather the social possibilities that arise with coordinated time off.

In the standard workweek, "days off work" and "social days" perfectly overlap as weekends. It is not possible to distinguish the value of a day off as apart from the value of greater social time with family and friends. A day off means a weekend, which means broadly shared time away from work.

The unemployed are an interesting case in this respect. In the world of time, the unemployed face a conundrum: they experience a large increase in their budget of free, unstructured time but simultaneously face a tangible scheduling constraint - other people still have to go to work.

The unemployed allow us to unbundle two aspects of the weekend. For the unemployed, all days are "days off"- they may keep busy, but they do not go to work for an employer. However, they are still limited by the same number of Saturdays and Sundays as everyone else. From a pure time budget perspective, weekends for the unemployed should not matter: there is just an undifferentiated sequence of days with plenty of unstructured time. What makes weekends special for the unemployed is that other people also have time off - two days per week when scheduling constraints are relaxed and nonworkdays can become social days.

Our difference-in-difference strategy for unbundling the weekend is laid out in Figure 1. We do not compare workers and the unemployed directly. Rather, we compare the "weekend effects" of these two groups. How much does an unemployed person's well-being increase on the weekend compared to the increase experienced by workers? This factors out the average difference in well-being between workers and the unemployed, focusing purely on differences in their day-of-week patterns. Do weekends cease to have meaning for the unemployed? How much of the weekend buzz can be sustained by not working during the week?

This research strategy coheres well with studies on the costs of working nonstandard hours. Nonstandard employment arrangements such as working nights and rotating shifts have been called "unsociable work" (Strazdins et al. 2006:394; Lesnard 2008). A considerable body of literature documents the negative effect of unsociable work hours on families: declines in marital satisfaction, problems with children, and greater risk of divorce (Presser 2003; White and Keith 1990; Strazdins et al. 2006). From a time scheduling perspective, nonstandard work hours are the inverse of unemployment: working when other 


\begin{tabular}{lllll} 
& Monday-Friday & Saturday/Sunday & Difference & Difference-in-Difference \\
\hline Worker & Work $\left(W_{w}\right)$ & $\begin{array}{l}\text { Non-Work and } \\
\text { Social }\left(N W S_{w}\right)\end{array}$ & $\begin{array}{l}\text { Weekend Effect } \\
\left(N W S_{w}-W_{w}\right)\end{array}$ & \\
\cline { 2 - 4 } Unemployed & Weekend Effect ${ }_{w}-$ \\
& $\begin{array}{l}\text { Non-Work } \\
\left(N W_{u}\right)\end{array}$ & $\begin{array}{l}\text { Non-Work and } \\
\text { Social }\left(N W S_{u}\right)\end{array}$ & $\begin{array}{l}\text { Weekend Effect } \\
\text { Weekend Effect }\end{array}$ & \\
& & $\left(N W S_{u}-N W_{u}\right)$ & \\
\hline
\end{tabular}

Figure 1: Time use by day of week for workers and the unemployed.

people have free time is the inverse of having free time when other people are working. Both are a breakdown in the temporal coordination of work and nonwork schedules, defecting from the standard workweek; they are different problems, but they represent two sides of the same coin in the scheduling constraint problem. This study helps to generalize the scholarship on unsociable work, viewing the problem from a broader theoretical lens, identifying parallel problems with nonwork hours, and specifically measuring the value of time using subjective well-being.

\section{Data Sets}

We use two independent data sets to test our hypotheses: the Gallup Daily Poll and the ATUS. First, we use the Gallup Daily Poll to examine subjective well-being by day of week for workers and the unemployed. Second, we use both Gallup and the ATUS to examine the amount of social time enjoyed by both groups each day of the week.

Since 2008, Gallup has interviewed at least 1,000 American adults each day and, by 2011, had sampled almost 1.3 million respondents. The Daily Poll includes questions on emotional wellbeing and labor force status and offers a unique opportunity to study small populations. For example, a key estimate of interest in this study is the well-being of unemployed people on weekends. However, less than 5 percent of the total sample is jobless ${ }^{4}$ and only one in four of those respondents were sampled on weekends. Despite this small baseline population, that leaves us with a sample of "unemployed people on the weekend" of

\footnotetext{
${ }^{4}$ This corresponds to an unemployment rate in the sample of 7.5 percent, which is not far from the official unemployment rate during this sampling time frame.
}

sociological science | www.sociologicalscience.com nearly 9,000 respondents - larger than what most social surveys collect for their entire samples.

In this study, we focus on the data collected between January 2009 and December 2011. Prior to 2009, the Gallup data do not allow us to identify the unemployed. Even without the 2008 data, the Daily Poll includes more than 970,000 respondents. Some 54 percent of them were either employed or self-employed at the time of survey. About 4.5 percent of all respondents, or 43,112 respondents, were unemployed: not working but "actively looking for employment" and able to start working if they were offered a job. Respondents are distributed approximately equally across the seven days of the week.

We focus on seven questions in the Daily Poll on positive and negative emotional well-being (Diener et al. 2010; Diener 1994; Kahneman et al. 2004). For positive well-being, the questions are whether respondents "smiled or laughed," experienced "enjoyment," and experienced "happiness" a lot on the previous day. Respondents answer yes or no to these questions. We consider this somewhat unfortunate, as a wider range of possible responses would capture more variation in wellbeing. Averaging the three responses, the variable for positive emotions ranges from 0 for people who experienced no positive emotions to 1 for people who experienced all of them. For negative well-being, four questions asked whether respondents experienced "worry," "sadness," "stress," or "anger" a lot on the previous day. These scores are likewise averaged to range from 0 for respondents who did not experience any negative emotion to 1 for respondents who experienced all four negative emotions (see the supplement for more details).

In addition to these measures of emotional well-being, the Daily Poll asks a simple question of how many hours respondents spent socially with friends or family the day before (including 
telephone, e-mail, or other online communications). With this question, we can examine how the amount of social time fluctuates from weekday to weekend.

To augment these data, and obtain a more robust measure of social time, we examine eight waves of the ATUS, from 2003 to 2011. The ATUS is collected by the Bureau of Labor Statistics and is an offshoot of the Current Population Survey (CPS), administered two to five months after a respondent has completed a CPS rotation. Respondents are asked to recount the activities of one single day, beginning at 4:00 a.m. "yesterday" and ending at 4:00 a.m. on the morning of the interview. From these records, we use the aggregate time spent with family and time spent with friends. The categories are not completely exclusive, as people can spend time with both friends and family simultaneously. However, this provides a more detailed, reliable, and comprehensive measurement of social time than the Gallup Poll, allowing us both to calibrate and to enrich that evidence 5

The 2003 to 2011 waves of the ATUS give a pooled sample of 6,212 unemployed respondents and 78,661 working people. The unemployment rate in the study (unemployed/labor force) is 7.3 percent. The survey substantially oversamples weekends. Half the sample is selected to report on a weekday (Monday to Friday) and half to report on a weekend (Saturday or Sunday). We treat the seven holidays included in the sample as weekend days (New Year's Day, Easter, Memorial Day, Fourth of July, Labor Day, Thanksgiving, and Christmas), as we do with the Gallup data. Missing data, primarily due to nonresponse on family income, reduces the final sample of labor force participants to 61,684 . The supplement shows the descriptive statistics for the ATUS data.

Respondents to both surveys are randomly selected to report on either weekdays or weekends. This simplifies the analysis of weekend effects, as individual characteristics should be exogenous to the day-of-week reporting. In the supplement, we show that for both data sets, those reporting on the weekend are more or less demographically identical to those reporting on weekdays.

\footnotetext{
${ }^{5}$ Note that the ATUS social time measures are based on copresence and do not include time spent on electronic communication.
}

There are small differences that achieve statistical significance owing to our very large sample sizes but that are substantively unimportant. In the ATUS data, the average age of both groups rounds down to 41 years, though the one-third of a year difference achieves statistical significance. The largest demographic difference is in the Gallup data, where the weekend respondents have a higher unemployment rate (8.8 percent) than weekday respondents (8.1 percent). Our full regression models adjust for these differences, but for the most part, a simple analysis of the raw data will be just as informative as, and perhaps more intuitive than, regression analysis.

\section{Model Specification}

There are five outcome variables in this study: first we focus on (1) positive emotions and (2) negative emotions, and next we focus on (3) social hours, (4) time spent with family, and (5) time spent with friends. The key treatment variable is the day of week (simplified as weekday vs. weekend), with employment status serving as a context variable for the treatment effect. To simplify the exposition, this article excludes persons out of the labor force ${ }^{6}$ The basic well-being and time use model, without control variables, is written as

$$
\begin{aligned}
Y_{i}=\alpha+ & \beta_{1} \text { Worker_Weekend }_{i}+\beta_{2} \text { Unemployed }_{i} \\
& +\beta_{3} \text { Unemp_Weekend }_{i}+\varepsilon_{i} .
\end{aligned}
$$

The parameters of this model give the simple average outcome (either well-being or social time) for four conditions:

1. Working people on weekdays (Monday to Friday): $\alpha$

2. Working people on weekends (Saturday, Sunday, and holidays): $\alpha+\beta_{1}$

3. Unemployed people on weekdays: $\alpha+\beta_{2}$

4. Unemployed people on weekends: $\alpha+\beta_{2}+$ $\beta_{3}$

\footnotetext{
${ }^{6}$ Data on people out of the labor force (OLF) are not relevant to computing coefficients listed in equation 1 . Analyses of OLF are available on request. The estimates are broadly similar to those for unemployed people.
} 
This approach is equivalent to - and gives identical results as - computing well-being and social time averages for each of the four groups. The comparison of weekend effects is simpler. The increase in well-being/social time on weekends for workers is given by $\beta_{1}$, whereas the weekend increase for the unemployed is given by $\beta_{3}$.

We extend this basic model in the usual way by adding in control variables for age, gender, race/ethnicity, children in the home, education, and family income 7 Because this study already provides random assignment to weekends, we expect that our raw weekend effects will be unaffected by the inclusion of control variables. However, the controls are likely to allow a more accurate estimate of $\beta_{2}$, the difference between workers and the unemployed during the week. This model is specified as

$$
\begin{aligned}
Y_{i}=\alpha & +\beta_{1} \text { Worker_Weekend }_{i}+\beta_{2} \text { Unemployed }_{i} \\
& +\beta_{3} \text { Unemp_Weekend }_{i}+\mathbf{X}_{k} \delta_{k}+\varepsilon_{i}, \quad(2)
\end{aligned}
$$

in which $\mathbf{X}_{k}$ is the $k \times 1$ vector of control variables and $\delta_{k}$ is the $1 \times k$ vector of coefficients.

\section{Descriptive Evidence: Emotional Well-Being on Week- ends versus Weekdays}

We begin with a descriptive analysis of the raw data, looking at weekend effects for workers and the unemployed. After giving an intuitive eyeball analysis, we check the robustness of this using regression adjustment for a host of sociodemographic covariates.

As a starting point, we plot the average positive and negative emotions of workers and the unemployed by day of week. In Figure 2, we start the graphs midweek to give a clear view of the beginning and ending of weekends (which occurs at the midpoint of our figures). This reveals three basic findings. First, weekend effects are clear, with a rise in positive feelings and a drop in negative emotions on weekends. Second, the unemployed have notably lower well-being every

\footnotetext{
${ }^{7}$ The list of control variables is calibrated as closely as possible across our two data sets. The only difference is that ATUS includes a measure of annual family income, whereas Gallup uses monthly family income.
}
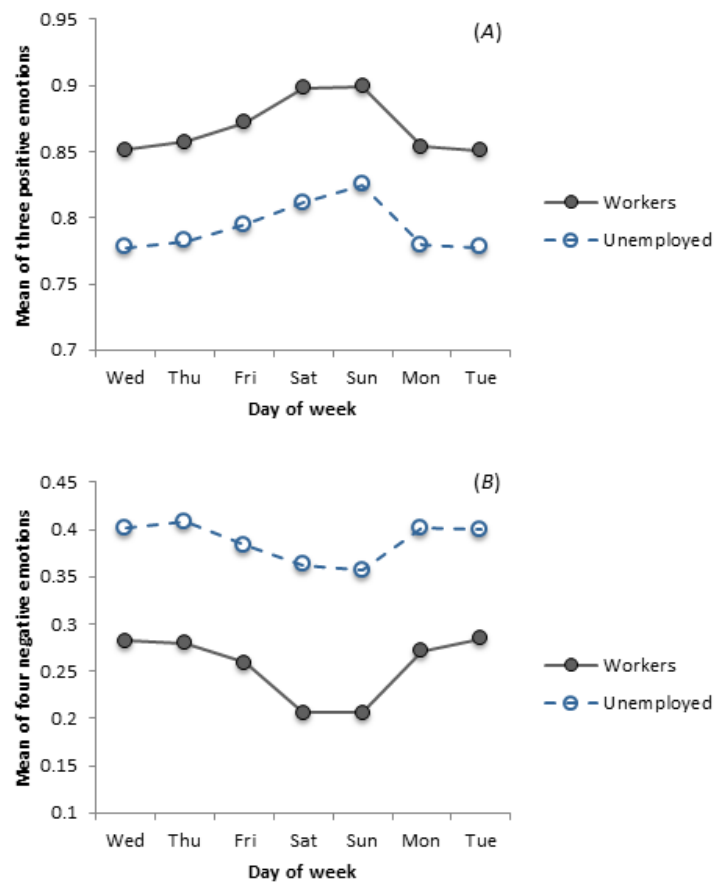

Figure 2: $(A)$ Positive and $(B)$ negative emotions by day of week. From Gallup Daily Poll, 2009-11.

day of the week (less happiness, more stress and worry) compared to workers. This is consistent with previous work on the experience of unemployment (e.g., Young 2012; Burgard, Brand, and House 2007). Third, the weekend effects for workers are strikingly similar to those of the unemployed. Though the unemployed do not go to work, they seem to be looking forward to the weekend in much the same way as workers.

To get another perspective on these data, in Table 1, we simplify the day-of-week comparison to weekends and weekdays and look at each emotion variable separately. For employed people, all three positive emotions increase on weekends by about 5 percent. Among the unemployed, the weekend boost is essentially the same. This is shown in the ratio of the weekend effects of the unemployed to the weekend effects for workers, which is 93 percent.

On weekends, workers see their negative emotions drop by about 24 percent on average (ranging from 10 percent to 35 percent, depending on the variable). Worry, stress, and anger show the largest drops, whereas sadness has the smallest 
Table 1: Average Number of Emotions Experienced, by Variable

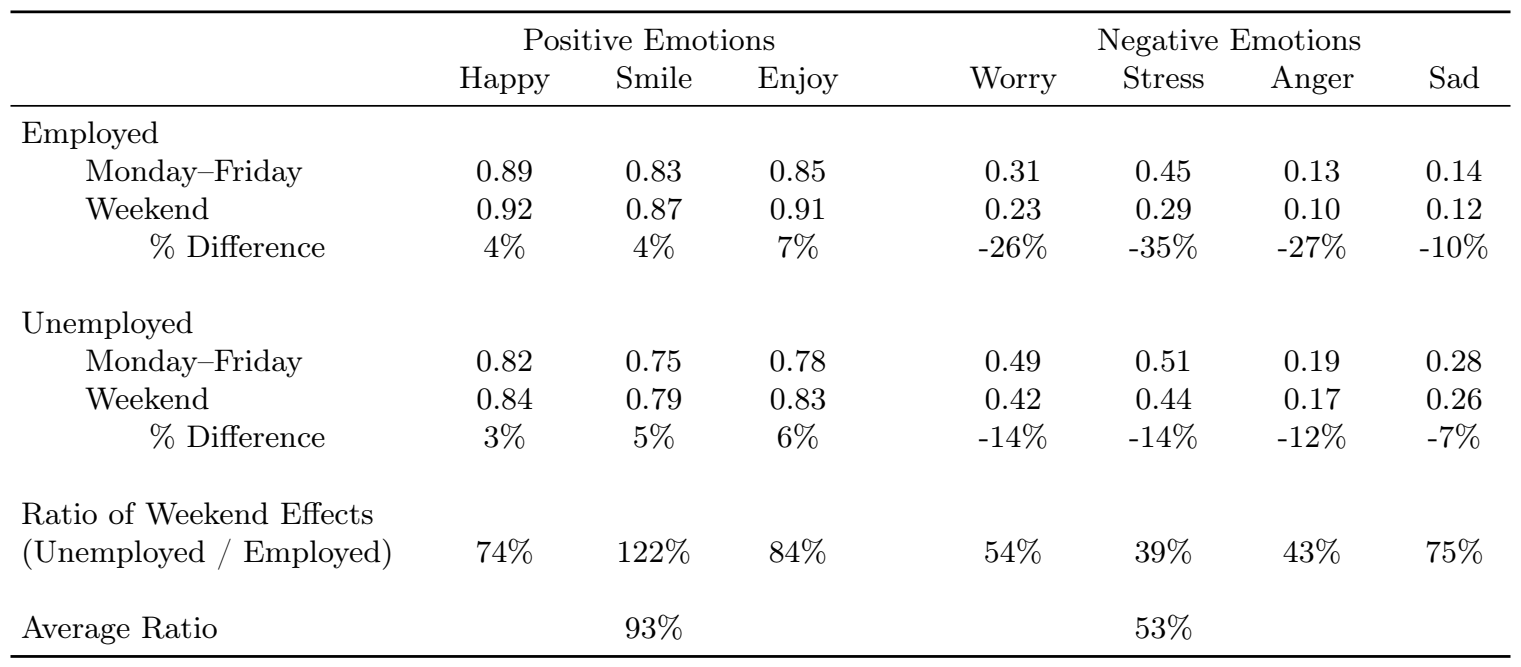

Note: Source: Gallup Daily Poll, 2009-11

decline. The jobless experience a drop in these emotions on weekends of about 12 percent. The average ratio indicates that the unemployed experience about 53 percent of the weekend reduction in negative emotions as workers 8

Weekends have greater effects on negative emotions, we suspect, for two reasons. First, there is simply a lower rate of reporting negative emotions. People are much more likely to report being happy than being angry, at least partly due to social acceptability bias. This low baseline rate of negative emotions makes the percentage changes look larger. Second, as we show in the regression results, the coefficients on almost all variables are larger in the analysis of negative well-being than in positive well-being. Reports of negative well-being seem more elastic to circumstances than reports of positive wellbeing. Positive and negative emotions are not

\footnotetext{
${ }^{8}$ The differences in this table can be thought of as semielasticities: the percentage difference in well-being owing to the difference in employment status. Using the marginal effects (unit differences in well-being) produces similar results. To exactly replicate our baseline regression model, the positive and negative groups would each be averaged (i.e., average positive and average negative emotions) before calculating the ratio of weekend effects. Doing so with marginal effects gives an average ratio of 84 percent and 63 percent for positive and negative wellbeing, respectively. That leads to a very similar overall conclusion. Table 1 gives a more intuitive representation of the data and gives very similar average ratios as reported in our full regression models later in the article.
}

simple reflections of one another but seem to capture some uniquely different aspects of emotional experience.

In any event, taken across both positive and negative measures of well-being, the jobless take in nearly three-quarters as much of the weekend effect that working people enjoy. However, there is a clear difference in that negative emotions decline more for workers than for the unemployed on weekends. A visible portion of the relief from stress, worry, and anger on the weekend is unique to working people. Weekends are a decompression time - a relief from negative feelings - for workers more than they are for the unemployed. Although the unemployed have more negative emotions during the week on every measure, the negatives do not drop on the weekend as much as they do for workers.

\section{Regression Results}

How robust are these conclusions to the addition of control variables for sociodemographic differences, including age, sex, race, family status, income, and education? In Table 2, we report the full details of our regression results for positive and negative emotions. Model 1 shows regression results for positive well-being by employment and weekend status. The weekend effect for the unemployed $(+0.038)$ is very similar to that for 
workers $(+0.043)$, both of which are highly significant. The difference in coefficients between the two groups (0.005) is small and nonsignificant.

Adding in controls (model 2) does not change the weekend effect estimates, as we expected, because both workers and the unemployed are randomly assigned to report on weekends. The change in the estimated weekend effects from model 1 to model 2 is barely visible, changing only slightly for the unemployed, and the difference is far from statistical significance. ${ }^{9}$ The controls do mute the negative baseline effect of unemployment, reducing it from -0.075 to -0.061 , indicating that some of the raw effect of unemployment is due to demographic differences 10 The point estimates indicate that the unemployed experience about 90 percent of the weekend effect that workers do.

It is worth noting that weekend effects are large relative to almost all other influences on wellbeing. The sociological significance of weekends for well-being is greater than sociodemographic factors such as marriage, race, and education but lesser than unemployment.

Model 3 looks at the determinants of negative well-being, and model 4 adds demographic controls. Weekends reduce negative feelings such as stress and worry for both groups, but more for workers $(-0.071)$ than for the unemployed $(-0.039)$. Again, these point estimates do not change when control variables are included (model 4). And the baseline effect of unemployment is significantly smaller in model 2 than in model $1(t$ statistic $=4.94)$. Although there is selection into unemployment based on observed covariates, this evidence continues to support the effectiveness of random assignment into weekends.

The point estimates indicate that the jobless experience 53 percent of the weekend effect that workers enjoy in lower negative emotions. The null hypothesis that the two groups have equal weekend effects is easily rejected, with a $t$-statistic of approximately 60 . There is clearly reliable

\footnotetext{
${ }^{9}$ The $t$-statistic is simply the difference in coefficients divided by the square root of the sum of the squared standard errors (Paternoster et al. 1998; Gelman and Stern 2006). For the difference in weekend effects for the unemployed from model 1 to model 2 , this is $(0.039-$ $0.038) / \sqrt{0.005^{2}+0.005^{2}}=0.14$.

${ }^{10}$ This difference is statistically significant with a $t$ statistic of -3.29 .
}

empirical support for weekends having unique, additional value for workers.

Finally, as seen with positive well-being, weekend effects rank among the most important influences on negative well-being. Even for the unemployed, weekend effects equal or outweigh factors such as education, gender, marriage, and parental status. Only unemployment itself has a clearly larger effect on well-being than do weekends. Averaging across positive and negative emotions, the unemployed experience about 73 percent of the weekend rise in well-being that workers enjoy.

\section{Does Social Time Explain Week- end Effects in Well-Being?}

Something about the standard workweek leads to higher well-being on weekends, even among the jobless. Going back to work on Monday provides limited explanation for the drop in well-being seen during the week. To what extent is this because social time declines during the week for both workers and the unemployed? Are the weekday patterns of social time similar to the patterns in well-being?

First, we plot social time use by day of week, using the raw data. Figure 3A, time spent with friends in the ATUS, shows large spikes around the weekends for both workers and the unemployed. Saturday is clearly the peak day for time with friends. The unemployed, compared to workers, spend more time with friends every day of the week. There is also some difference in the weekend effects for workers and the unemployed. For workers, time with friends is elevated on Friday, Saturday, and Sunday. For the unemployed, there is more noise in the day-to-day estimates, but their time with friends appears elevated on Friday and Saturday only; by Sunday, time with friends has returned to their weekday average.

Figure 3B, time with family, also shows clear weekend effects, with Saturday and Sunday being roughly equal peak days of family time. The unemployed spend more time with family Monday to Friday, and their weekend increase is about half of what workers experience.

It is not the case that the unemployed have no one with whom to spend time on weekdays. Their social time is certainly lower than on weekends 
Table 2: Determinants of Positive Emotions, Negative Emotions, and Social Hours

\begin{tabular}{|c|c|c|c|c|c|c|}
\hline & \multicolumn{2}{|c|}{ Positive Emotions } & \multicolumn{2}{|c|}{ Negative Emotions } & \multicolumn{2}{|c|}{ Social Hours } \\
\hline & $(1)$ & $(2)$ & (3) & (4) & $(5)$ & (6) \\
\hline Unemployed & $\begin{array}{r}-0.075 * \\
(0.003)\end{array}$ & $\begin{array}{r}-0.061 * \\
(0.003)\end{array}$ & $\begin{array}{c}0.122 * \\
(0.003)\end{array}$ & $\begin{array}{c}0.101 * \\
(0.003)\end{array}$ & $\begin{array}{c}0.910 * \\
(0.040)\end{array}$ & $\begin{array}{r}0.919 * \\
(0.039)\end{array}$ \\
\hline Unemployed $\times$ Weekend & $\begin{array}{r}0.038 * \\
(0.005)\end{array}$ & $\begin{array}{r}0.039 * \\
(0.005)\end{array}$ & $\begin{array}{r}-0.039 * \\
(0.005)\end{array}$ & $\begin{array}{r}-0.039 * \\
(0.005)\end{array}$ & $\begin{array}{c}0.888 * \\
(0.072)\end{array}$ & $\begin{array}{r}0.908 * \\
(0.069)\end{array}$ \\
\hline Worker $\times$ Weekend & $\begin{array}{c}0.043 * \\
(0.001)\end{array}$ & $\begin{array}{r}0.043 * \\
(0.001)\end{array}$ & $\begin{array}{c}-0.071 * \\
(0.001)\end{array}$ & $\begin{array}{r}-0.071 * \\
(0.001)\end{array}$ & $\begin{array}{c}2.080 * \\
(0.019)\end{array}$ & $\begin{array}{r}2.083 * \\
(0.018)\end{array}$ \\
\hline Age & & $\begin{array}{r}-0.001 * \\
(0.000)\end{array}$ & & $\begin{array}{r}-0.001 * \\
(0.000)\end{array}$ & & $\begin{array}{r}-0.044 * \\
(0.001)\end{array}$ \\
\hline Female & & $\begin{array}{r}0.007 * \\
(0.001)\end{array}$ & & $\begin{array}{c}0.033 * \\
(0.001)\end{array}$ & & $\begin{array}{r}0.236 * \\
(0.016)\end{array}$ \\
\hline One or more children & & $\begin{array}{r}-0.010 * \\
(0.001)\end{array}$ & & $\begin{array}{c}0.032 * \\
(0.001)\end{array}$ & & $\begin{array}{r}0.454 * \\
(0.018)\end{array}$ \\
\hline Married & & $\begin{array}{l}0.026 * \\
(0.001)\end{array}$ & & $\begin{array}{r}-0.023 * \\
(0.001)\end{array}$ & & $\begin{array}{r}0.491 * \\
(0.019)\end{array}$ \\
\hline Monthly income & & $\begin{array}{c}0.004 * \\
(0.000)\end{array}$ & & $\begin{array}{c}-0.006 * \\
(0.000)\end{array}$ & & $\begin{array}{r}0.032 * \\
(0.002)\end{array}$ \\
\hline \multicolumn{7}{|l|}{ Education $^{\mathrm{a}}$} \\
\hline Less than high school & & $\begin{array}{r}-0.022 * \\
(0.003)\end{array}$ & & $\begin{array}{c}0.034 * \\
(0.003)\end{array}$ & & $\begin{array}{r}-0.403 * \\
(0.045)\end{array}$ \\
\hline Some college & & $\begin{array}{r}0.005 * \\
(0.001)\end{array}$ & & $\begin{array}{r}0.017 * \\
(0.002)\end{array}$ & & $\begin{array}{c}0.042 \\
(0.023)\end{array}$ \\
\hline College degree & & $\begin{array}{r}0.006 * \\
(0.001)\end{array}$ & & $\begin{array}{r}0.011 * \\
(0.002)\end{array}$ & & $\begin{array}{r}-0.448 * \\
(0.024)\end{array}$ \\
\hline Post graduate education & & $\begin{array}{c}0.003 \\
(0.002)\end{array}$ & & $\begin{array}{c}0.021 * \\
(0.002)\end{array}$ & & $\begin{array}{r}-0.483 * \\
(0.026)\end{array}$ \\
\hline \multicolumn{7}{|l|}{ Race/ethnicity ${ }^{\mathrm{b}}$} \\
\hline Black & & $\begin{array}{c}0.005 * \\
(0.002)\end{array}$ & & $\begin{array}{c}-0.062 * \\
(0.002)\end{array}$ & & $\begin{array}{r}0.219 * \\
(0.031)\end{array}$ \\
\hline Asian & & $\begin{array}{r}-0.023 * \\
(0.004)\end{array}$ & & $\begin{array}{r}-0.018 * \\
(0.004)\end{array}$ & & $\begin{array}{r}-0.844 * \\
(0.058)\end{array}$ \\
\hline Hispanic & & $\begin{array}{c}0.005 * \\
(0.002)\end{array}$ & & $\begin{array}{r}-0.008 * \\
(0.002)\end{array}$ & & $\begin{array}{r}-1.257 * \\
(0.030)\end{array}$ \\
\hline Other & & $\begin{array}{r}-0.010 * \\
(0.003)\end{array}$ & & $\begin{array}{c}0.010 * \\
(0.003)\end{array}$ & & $\begin{array}{r}0.202 * \\
(0.045)\end{array}$ \\
\hline Constant & $\begin{array}{c}0.856 * \\
(0.001)\end{array}$ & $\begin{array}{c}0.858 * \\
(0.002)\end{array}$ & $\begin{array}{c}0.277 * \\
(0.001)\end{array}$ & $\begin{array}{c}0.326 * \\
(0.003)\end{array}$ & $\begin{array}{c}4.986 * \\
(0.010)\end{array}$ & $\begin{array}{r}6.367 * \\
(0.040)\end{array}$ \\
\hline Observations & 503,284 & 503,284 & 503,284 & 503,284 & 333,354 & 333,354 \\
\hline$R^{2}$ & 0.011 & 0.019 & 0.026 & 0.045 & 0.060 & 0.105 \\
\hline
\end{tabular}

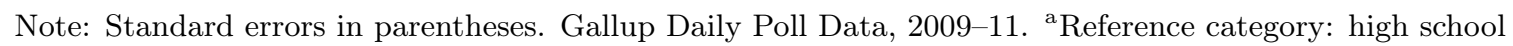
diploma. ${ }^{\mathrm{b}}$ Reference category: white.

$* \mathrm{p}<0.01$ 

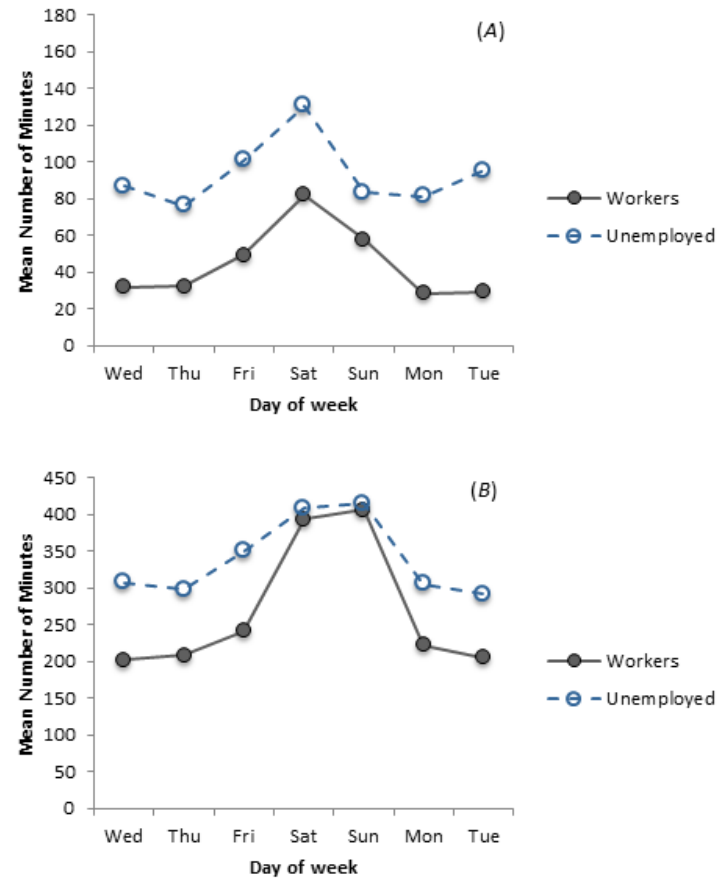

Figure 3: Time with $(A)$ friends and $(B)$ family by day of week. From American Time Use Survey, 2003-11.

but remains higher than the amount of social time that working people have Monday to Friday. A full assessment of the evidence clearly needs to take this fact into account. However, in supplementary analyses not reported here, the amount of time the unemployed spend alone is also higher Monday to Friday ( +1.8 hours per day) than on weekends.

In summary, there are strong weekend effects in social time for both workers and the unemployed. This provides a promising account of why both groups have similar weekend effects in their well-being.

Table 3 shows the full regression results for social time in the ATUS. Model 7 shows the results for time spent with friends including unemployment and weekend status without controls. For the unemployed, time with friends increases by 18.5 minutes, compared to 36.7 minutes for workers. With the full set of controls in model 8 , the weekend effect for the unemployed rises slightly to 20.2 minutes and is unchanged for workers at 36.6 minutes. The difference in weekend effects is statistically significant $(t$-statistic $=3.69)$.
Model 9 shows estimated weekend effects for time spent with family. Working people increase the amount of time spent with family on weekends by 189 minutes - more than three hours. For the unemployed, the increase is 103 minutes-roughly an hour and a half. Adding in demographic controls in model 10 changes the estimate for the unemployed weekend effect slightly, which drops to 97 minutes. Time spent with family increases by half as much for the unemployed as it does for workers. The difference is due to the greater ability of the unemployed to spend more hours with family during the week. Nonetheless, a clear limitation on social time with family during the week remains.

As a reference point, we also consider household labor. Chores around the house are not subject to social network constraints in the way that social time is. People do not need to coordinate with social others to productively engage in household labor: cleaning, cooking, yard maintenance, household repairs, and the like. Most household labor, we argue, is about as productively done alone as with others, and we expect to see no weekend effect in household work among the unemployed. Figure 4 shows that this is indeed the case.

Whereas workers increase their household work on weekends, the unemployed have a stable, high level of housework. Workers, in effect, coordinate their household labor not to conflict with their market work times. The jobless spend about 2 hours and 15 minutes per day on household workequivalent to what workers do on weekends. With a "day off," workers and the unemployed spend

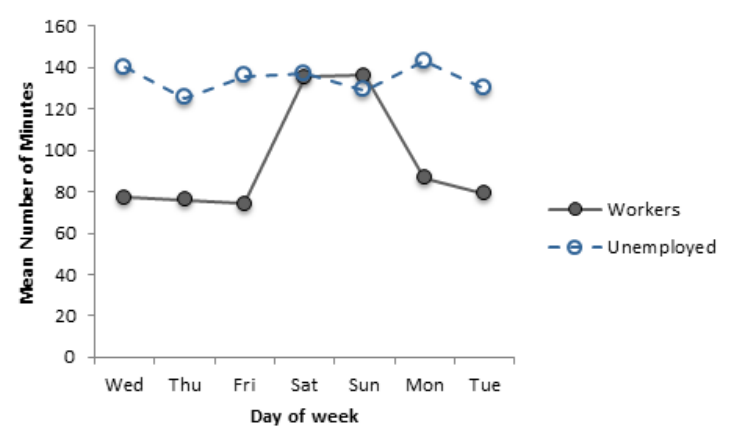

Figure 4: Time on housework by day of week. From American Time Use Survey, 2003-11. 
Table 3: Determinants of Time Use: Friends, Family and Housework

\begin{tabular}{|c|c|c|c|c|c|c|}
\hline & \multicolumn{2}{|c|}{ Time with Friends } & \multicolumn{2}{|c|}{ Time with Family } & \multicolumn{2}{|c|}{ Household Work } \\
\hline & $(7)$ & $(8)$ & $(9)$ & $(10)$ & $(11)$ & $(12)$ \\
\hline Unemployed & $\begin{array}{c}54.8 * \\
(3.3)\end{array}$ & $\begin{array}{c}36.4 * \\
(3.2)\end{array}$ & $\begin{array}{c}96.2 * \\
(6.2)\end{array}$ & $\begin{array}{c}132.1 * \\
(5.4)\end{array}$ & $\begin{array}{c}57.2 * \\
(3.0)\end{array}$ & $\begin{array}{c}75.3 * \\
(3.0)\end{array}$ \\
\hline Unemployed $\times$ Weekend & $\begin{array}{c}18.5 * \\
(4.4)\end{array}$ & $\begin{array}{c}20.2 * \\
(4.3)\end{array}$ & $\begin{array}{c}103.2 * \\
(8.4)\end{array}$ & $\begin{array}{c}96.9 * \\
(7.2)\end{array}$ & $\begin{array}{c}-1.6 \\
(4.1)\end{array}$ & $\begin{array}{c}-3.7 \\
(3.9)\end{array}$ \\
\hline Worker $\times$ Weekend & $\begin{array}{c}36.7 * \\
(1.2)\end{array}$ & $\begin{array}{c}36.6 * \\
(1.1)\end{array}$ & $\begin{array}{r}189.2 * \\
(2.2)\end{array}$ & $\begin{array}{r}187.4 * \\
(1.9)\end{array}$ & $\begin{array}{c}58.4 * \\
(1.1)\end{array}$ & $\begin{array}{c}58.7 * \\
(1.1)\end{array}$ \\
\hline Constant & $\begin{array}{c}33.6 * \\
(0.8)\end{array}$ & $\begin{array}{r}143.1 * \\
(2.8)\end{array}$ & $\begin{array}{r}211.9 * \\
(1.6)\end{array}$ & $\begin{array}{c}1.2 \\
(4.6)\end{array}$ & $\begin{array}{l}77.6 * \\
(0.8)\end{array}$ & $\begin{array}{r}-25.1 * \\
(2.5)\end{array}$ \\
\hline Demographic controls & No & Yes & No & Yes & No & Yes \\
\hline Observations & 61,684 & 61,684 & 61,684 & 61,684 & 61,684 & 61,684 \\
\hline Adjusted $R^{2}$ & 0.022 & 0.087 & 0.107 & 0.349 & 0.047 & 0.111 \\
\hline
\end{tabular}

Note: Standard errors in parentheses. American Time Use Data 2003-11. The dependent variable in the ATUS is in minutes, while the Gallup data in Table 2 are reported in hours. To maintain comparable precision, estimates here are reported to the first decimal place.

$* \mathrm{p}<0.01$

equal amounts of time on household work. It is just that the unemployed have five more days off per week. If social time were not subject to network constraints, this is what we would expect patterns of time with friends and family to look like.

In Table 3, models 11 and 12 show that although there are clear weekend effects in household labor for workers, there is no weekend effect at all for the unemployed.

The Gallup data also provide evidence of how time use varies by day of week. Figure 5 shows

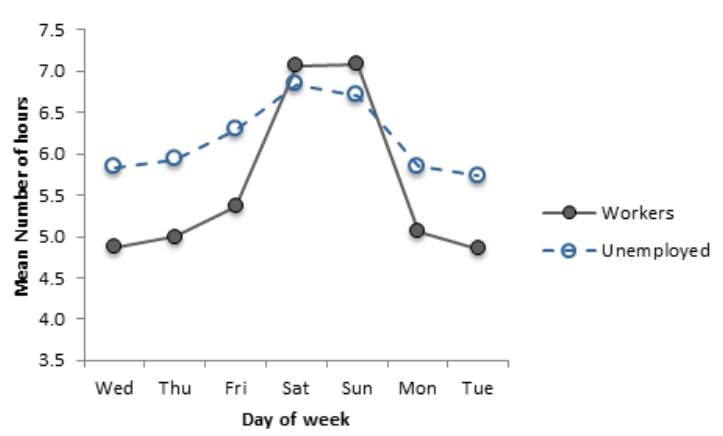

Figure 5: Social hours by day of week. From Gallup Daily Poll, 2009-11. a general measure of "social hours" for weekends and weekdays from the Daily Poll. The results are similar to the ATUS data. In Table 2, models 5 and 6 show that workers see an increase in social time of 2.1 hours (125 minutes) per day on weekends, whereas the unemployed see an increase of 0.9 hours (55 minutes). Thus, in the Gallup data, the unemployed experience 43 percent of the weekend effect in social time. During the week, the unemployed spend nearly an extra one social hour per day more than workers.

In summary, the unemployed experience 55 percent of the weekend effect in time spent with friends that the employed experience, 52 percent of the weekend effect in time with family, and 43 percent of the social hours effect in the Gallup data. Overall, this suggests that weekends should be about half as important for the unemployed as they are for workers. This does not seem to provide a complete explanation of why the unemployed enjoy three-quarters of the weekend effect in well-being. But the commonality of the patterns in well-being and social time suggest this is a prominent explanation. The next step is to test the underlying assumption that social hours increase well-being, and if so, do they increase well-being by enough to explain the weekend effects? 
In Table 4, we incorporate the Gallup social hours variable into the initial well-being regressions. For roughly one-third of our observations, questions about social hours were not asked. This reduces the sample size to about 333,000. Model 13 , the determinants of positive emotions, replicates model 2 with the smaller sample. None of the estimates of interest are meaningfully affected by the sample size reduction. However, including social hours (model 14) does have a clear effect. The weekend effect for the unemployed drops by 38 percent, from 0.040 to 0.025 , and drops for workers by 77 percent (from 0.044 to 0.010 ). The number of social hours explains about 57 percent of the increase in positive emotions on weekends. This is about what the simple day-of-week analyses suggested.

For negative emotions, models 15 and 16 show that when social hours are included, the weekend effects fall by 28 percent for the unemployed and 31 percent for workers. Thus, social hours explain about 29 percent of the reduction in negative feelings on weekends. This is somewhat less than expected from the simple day-of-week patterns. The reason is that the number of social hours people spend has less of an effect on negative emotions like stress and sadness (0.011 in absolute value) than it does on positive emotions (0.016 in absolute value).

Overall, averaging across positive and negative emotions for both workers and the unemployed, the number of social hours people enjoy explains 43 percent of the weekend well-being effects 11 There remain weekend effects in wellbeing that are both statistically and sociologically significant for both workers and the unemployed, that cannot be explained by social hours alone.

Another important result from Table 4 is that social hours do not explain the baseline effect of unemployment. This sheds light on why the unemployed have lower well-being, even though they have more social time than workers. Social time during the week does partly compensate for the distress of unemployment. Without it, the unemployed would be even more distressed. However, the negative effect of unemployment is very large compared to the gain in social hours. For positive well-being, the effect of unemployment is -0.080 ,

\footnotetext{
${ }^{11}$ This is the average reduction in the four weekend coefficients as a result of including social hours in the regression models.
}

which is roughly five times as large as the effect of a social hour. For negative well-being, the effect of unemployment is 0.118 , which is 10 times the effect of a social hour. In other words, it would take five extra hours of social time each day to compensate for the drop in happiness among the unemployed and 10 social hours to compensate for the increase in stress and sadness. But, in the Gallup data, unemployment gives people an extra one hour of social time. Unemployment is a very costly way to leverage extra social time.

\section{Discussion and Conclusion}

What is it about time off work that people most value: avoiding the disutility of labor or the opportunity for greater social contact? To what extent does extra free time give a valued benefit that can offset the socioeconomic and psychological costs of unemployment? Both these questions feed into a basic understanding of time. Is time best understood as analogous to money, in which the primary concern is one's budget of free time? Or is time better understood as a network good, in which the marginal value of extra time can vary widely and depends on the schedules of others (Winship 2009; DiMaggio and Garip 2012; Bittman 2005)?

The analyses here present a series of new and important social facts. First, weekends have an effect on well-being that is clear and large relative to other determinants of well-being: weekend effects are sociologically important (Helliwell and Wang 2011). However, the benefits of weekends are not primarily due to having time off from work: the jobless experience about three-quarters of the benefit of weekends. Only one-quarter of the weekend rise in well-being can be readily attributed to rest from work.

Second, the amount of social time that people have increases substantially on weekends, for both workers and the unemployed. Increases in social time explain nearly half of the weekend rise in well-being. A large part of why weekends are better than weekdays is that friends and families are able spend more time together. Free time during the week does not easily translate into greater social time. Absent the social coordination of the standard workweek, workers would see 
Table 4: Determinants of Well-Being, Including Social Hours

\begin{tabular}{|c|c|c|c|c|}
\hline & \multicolumn{2}{|c|}{ Positive Emotions } & \multicolumn{2}{|c|}{ Negative Emotions } \\
\hline & $(13)$ & (14) & $(15)$ & $(16)$ \\
\hline Unemployed & $\begin{array}{r}-0.062 * \\
(0.003)\end{array}$ & $\begin{array}{r}-0.080 * \\
(0.003)\end{array}$ & $\begin{array}{c}0.107 * \\
(0.003)\end{array}$ & $\begin{array}{r}0.118 * \\
(0.003)\end{array}$ \\
\hline Unemployed $\times$ Weekend & $\begin{array}{r}0.040 * \\
(0.006)\end{array}$ & $\begin{array}{r}0.025 * \\
(0.005)\end{array}$ & $\begin{array}{c}-0.036 * \\
(0.006)\end{array}$ & $\begin{array}{r}-0.026 * \\
(0.006)\end{array}$ \\
\hline Worker $\times$ Weekend & $\begin{array}{c}0.044 * \\
(0.001)\end{array}$ & $\begin{array}{l}0.010 * \\
(0.001)\end{array}$ & $\begin{array}{c}-0.072 * \\
(0.001)\end{array}$ & $\begin{array}{r}-0.050 * \\
(0.001)\end{array}$ \\
\hline Social hours & & $\begin{array}{r}0.016 * \\
(0.000)\end{array}$ & & $\begin{array}{r}-0.011 * \\
(0.000)\end{array}$ \\
\hline Constant & $\begin{array}{r}0.858 * \\
(0.003)\end{array}$ & $\begin{array}{r}0.756 * \\
(0.003)\end{array}$ & $\begin{array}{c}0.323 * \\
(0.003)\end{array}$ & $\begin{array}{r}0.389 * \\
(0.003)\end{array}$ \\
\hline Demographic controls & Yes & Yes & Yes & Yes \\
\hline $\begin{array}{l}\text { Observations } \\
R^{2}\end{array}$ & $\begin{array}{c}333,354 \\
0.020\end{array}$ & $\begin{array}{c}333,354 \\
0.065\end{array}$ & $\begin{array}{c}333,354 \\
0.047\end{array}$ & $\begin{array}{c}333,354 \\
0.063\end{array}$ \\
\hline
\end{tabular}

Note: Standard errors in parentheses. Gallup Daily Poll, 2009-11.

$* \mathrm{p}<0.01$

much smaller gains in sociability and well-being on their days off.

Third, a significant part of weekend well-being remains unexplained by either time off work or extra social hours. There is something in addition to social hours that makes weekends better than weekdays for both workers and the unemployed.

Social multipliers stemming from having a large portion of the workforce with a shared day off may explain the residual weekend effects. For example, those with a day off may interact with the world in a more positive way - they are less busy, are less tired, and have more emotional energy to share with others. This increases the quality of their social interactions and creates a positive externality for the individuals who interact with them (Fowler and Christakis 2008). When a large portion of the population does not go into work on a given day, not only the quantity but also the quality of social interaction increases. This, in turn, suggests that the value of social hours is greater on weekends than during the week. From a different perspective, when the majority of the workforce has a day off, it may change social expectations and normalize "not working." This allows everyone to relax more and creates a sense that the day is meant to be enjoyed, increasing the value of nonwork time for everyone, whether that time is spent with company or alone. The unemployed may particularly appreciate days when the rest of society becomes more similar to them, making their nonwork status less salient and unusual. From this perspective, weekend well-being depends on a general expectation of leisure but not on the specific availability of one's own family and friends ${ }^{12}$ Both of these factors likely help explain why the quantity of social hours explains only half of the weekend effect on well-being.

The findings of this study also speak directly to the experience of unemployment. In a time famine age, the unemployed are people who have gained large amounts of free time. This has come at a steep cost: a loss of income and great anxiety about their status as productive members of society (Young 2012; Burgard et al. 2007; Newman 1999). Nevertheless, the jobless may see their circumstance as a mixture of costs and benefits (Feldstein and Altman 2007; Krueger and Meyer 2002), resenting joblessness but simultaneously valuing extra time. We find supporting evidence,

\footnotetext{
${ }^{12}$ This is a question of whether other people's work schedules create "global" or "local" externalities (DiMaggio and Garip 2012).
} 
but only weakly so. The jobless spend more social time with people than working people do (at least an extra hour per day during the week), showing a tangible benefit of unemployment. However, the social-psychological costs of unemployment are very large relative to the extra social time that is available during unemployment. Social time does moderate the distress of unemployment, but the jobless would need 5 to 10 times more hours of social contact than they actually get to fully alleviate the social-psychological distress of job loss.

The dilemma of the unemployed is that, although they have additional free time during the week, other people still have to go to work. Equivalently, working people may think of their jobs as "a drag" because they compare their working lives to their lives on the weekend - not to the achievable alternative of staying home during the week. The opportunity cost of working and the benefits of free time both depend on the schedules and availability of others.

The standard workweek coordinates work life in a way that maximizes social time and wellbeing on weekends and creates a strong perceived relationship between workdays and unhappiness. Yet it also means that individuals cannot easily avoid the unhappiness of the workweek by not going to work. Individual days off during the week seem to fall very far short of the experience of shared weekends. This emphasizes that the standard workweek is an institutional structure that both enables and constrains (e.g., Brinton and Nee 1998; Ingram and Clay 2000).

Because time is a network good, it is hard to find individual solutions to problems of time pressure. Weekend well-being is a collectively produced social good; time famine is in part a collectively produced coordination failure. In recent years, there has been much focus on achieving greater individual flexibility in work schedules. Such flexibility no doubt has many benefits, but the downside of time flexibility is that it moves us toward the privatization of personal schedules and ever further from coordinated social time. Privatized personal schedules generate individual convenience but make unplanned social time increasingly difficult to find: they set up the "bowling alone" problem. Ultimately, the more successful solution may be to find freedom in con-

sociological science | www.sociologicalscience.com straint: greater standardization of the times for work and the times for life.

\section{References}

Åberg, Yvonne. 2009. "The Contagiousness of Divorce." Pp. 342-64 in The Oxford Handbook of Analytical Sociology, edited by Peter Hedstrom and Peter Bearman. Oxford: Oxford University Press.

Bianchi, S. M., J. P. Robinson, and M. A. Milkie. 2007. Changing Rhythms of American Family Life. New York: Russell Sage Foundation.

Bittman, Michael. 2005. "Sunday Working and Family Time." Labour and Industry 16: 59-83. http://dx.doi.org/10.1080/ 10301763.2005 .10722031

Blundell, Richard and Thomas MaCurdy. 1999. "Labor Supply: A Review of Alternative Approaches." Pp. 1559-1695 in Handbook of Labor Economics, Vol. 3, edited by Orley Ashenfelter and David Card. Amsterdam: North-Holland. http://dx.doi.org/ 10.1016/S1573-4463(99)03008-4

Brinton, Mary and Victor Nee, eds. 1998. The New Institutionalism in Sociology. New York: Russell Sage Foundation.

Burgard, Sarah A., Jennie E. Brand, and James S. House. 2007. "Toward a Better Estimation of the Effect of Job Loss on Health." Journal of Health and Social Behavior 48:369-84. http://dx.doi.org/10 1177/002214650704800403

Collins, Randall. 2004. Interaction Ritual Chains. Princeton, NJ: Princeton University Press.

Diener, Ed. 1994. "Assessing Subjective WellBeing: Progress and Opportunities." Social Indicators Research 31:103-57. http://dx doi.org/10.1007/BF01207052

Diener, Ed, Daniel Kahneman, William Tov, and Raksha Arora. 2010. "Income's Association with Judgments of Life Versus Feeling." Pp. 315 in International Differences in Well-Being, edited by E. Diener, J. F. Helliwell, and D. Kahneman. New York: Oxford University Press.

DiMaggio, Paul and Joseph Cohen. 2005. "Information Inequality and Network Externalities: 
A Comparative Study of the Diffusion of Television and the Internet." Pp. 227-67 in The Economic Sociology of Capitalism, edited by Victor Nee and Richard Swedberg. Princeton, NJ: Princeton University Press.

DiMaggio, Paul and Filiz Garip. 2011. "How Network Externalities Can Exacerbate Intergroup Inequality." American Journal of Sociology 116:1887-1933. http://dx.doi.org/ 10.1086/659653

DiMaggio, Paul and Filiz Garip. 2012. "Network Effects and Social Inequality." Annual Review of Sociology 38:93-118. http://dx.doi.org/ 10.1146/annurev.soc.012809.102545

Evans, James, Gideon Kunda and Stephen Barley. 2004. "Beach Time, Bridge Time and Billable Hours: The Temporal Structure of Technical Contracting." Administrative Science Quarterly 49:1-38. http://dx.doi.org/10 2307/4131454

Feldstein, Martin and Daniel Altman. 2007. "Unemployment Insurance Savings Accounts." Tax Policy and the Economy 21:35-64.

Foss, Clive. 2004. "Stalin's Topsy-Turvy Work Week." History Today, September, 46-47.

Fowler, James and Nicholas Christakis. 2008. "Dynamic Spread of Happiness in a Large Social Network: Longitudinal Analysis over 20 Years in the Framingham Heart Study." British Medical Journal 337:a2338. http: //dx.doi.org/10.1136/bmj.a2338

Gelman, Andrew and Hal Stern. 2006. "The Difference between 'Significant' and 'Not Significant' Is Not Itself Statistically Significant." American Statistician 60:328-31. http://dx doi.org/10.1198/000313006X152649

Helliwell, John and Shun Wang. 2011. "Weekends and Subjective Well-Being." NBER Working Paper 17180.

Hochschild, A. R. 1997. The Time Bind: When Work Becomes Home and Home Becomes Work. New York: Metropolitan Books.

Hornstein, Andreas. 2002. "Towards a Theory of Capacity Utilization: Shiftwork and the Workweek of Capital." Federal Reserve Bank of Richmond Economic Quarterly 88: 65-86.

Ingram, Paul and Karen Clay. 2000. "The Choicewithin-Constraints New Institutionalism and
Implications for Sociology." Annual Review of Sociology 26:525-46. http://dx.doi.org/ 10.1146/annurev.soc.26.1.525

Jacobs, Jerry and Kathleen Gerson. 2004. The Time Divide: Work, Family, and Gender Inequality. Cambridge, MA: Harvard University Press.

Jevons, Stanley. 1890. Money and the Mechanism of Exchange. New York: D. Appleton.

Kahneman, Daniel, Alan Krueger, David Schkade, Norbert Schwarz, and Arthur Stone. 2004. "A Survey Method for Characterizing Daily Life Experience: The Day Reconstruction Method." Science 306:1776-80.

Keane, Michael. 2011. "Labor Supply and Taxes: A Survey." Journal of Economic Literature 49:961-1075.

Krueger, Alan and Bruce Meyer. 2002. "Labor Supply Effects of Social Insurance." Pp. 2327-92 in Handbook of Public Economics, Vol. 4, edited by Alan Auerbach and Martin Feldstein. Amsterdam: North-Holland. http://dx.doi.org/10 1016/S1573-4420(02)80012-X

Leclerc, France, Bernd Schmitt, and Laurette Dube. 1995. "Waiting Time and Decision Making: Is Time Like Money?" Journal of Consumer Research 22:110-19. http://dx doi.org/10.1086/209439

Lesnard, Laurent. 2008. "Off-Scheduling within Dual-Earner Couples: An Unequal and Negative Externality for Family Time." American Journal of Sociology 114:447-90. http: //dx.doi.org/10.1086/590648

Levin, Eric and Robert Wright. 2001. "Unemployment Insurance, Moral Hazard, and Economic Growth." International Advances in Economic Research 7:373-84. http://dx doi.org/10.1007/BF02295767

Lyness, Karen, Janet Gornick, Pamela Stone, and Angela Grottoa. 2012. "It's All about Control: Worker Control over Schedule and Hours in Cross-National Context." American Sociological Review 77:1023-49. http://dx doi.org/10.1177/0003122412465331

Newman, Katherine S. 1999. Falling from Grace: Downward Mobility in the Age of Affluence. Berkeley: University of California Press. 
Paternoster, Raymond, Robert Brame, Paul Mazerolle, and Alex Piquero. 1998. "Using the Correct Statistical Test for the Equality of Regression Coefficients." Criminology 36:859-66. http://dx.doi.org/10.1111/j 1745-9125.1998.tb01268.x

Presser, Harriet B. 2003. Working in a 24/7 Economy: Challenges for American Families. New York: Russell Sage Foundation.

Putnam, Robert. 2000. Bowling Alone: The Collapse and Revival of American Community. New York: Simon and Schuster.

Robinson, John P. and Geoffrey Godbey. 2000. Time for Life: The Surprising Ways Americans Use Their Time. 2nd ed. University Park: Pennsylvania State University Press.

Rybczynski, Witold. 1991. Waiting for the Weekend. New York: Viking Press.

Schor, Juliet B. 1991. The Overworked American. New York: Basic Books.

Shapiro, Carl and Hal Varian. 1999. Information Rules: A Strategic Guide to the Network Economy. Boston: Harvard Business School Press.

Stovel, Katherine and Christine Fountain. 2009. "Matching." Pp. 365-90 in The Handbook of Analytic Sociology, edited by Peter Hedstrom and Peter Bearman. Oxford: Oxford University Press.

Strazdins, Lyndall, Mark S. Clements, Rosemary J. Korda, Dorothy H. Broom, and Rennie M. D'Souza. 2006. "Unsociable Work? Nonstandard Work Schedule, Family Relationships, and Children's WellBeing." Journal of Marriage and Family 68:394-410. http://dx.doi.org/10.1111/ j.1741-3737.2006.00260.x

Verbakel, Ellen and Thomas DiPrete. 2008. "The Value of Non-Work Time in Cross-National Quality of Life Comparisons: The Case of the United States vs. the Netherlands." Social Forces 87:679-712. http://dx.doi.org/10 $1353 /$ sof.0.0125

Weiner, Rachel. 2011. "State of the Union 2011: Paul Ryan Responds That Government Spending Needs to Stop." Washington Post, January 25. Retrieved September 23, 2012, http:// voices.washingtonpost.com/44/2011/01/ paul-ryans-response-government.html.
White, Lynn and Bruce Keith. 1990. "The Effect of Shift Work on the Quality and Stability of Marital Relations." Journal of Marriage and Family 52:453-62. http://dx.doi.org/ $10.2307 / 353039$

Williams, Joan. 2010. Re-shaping the Work Family Debate: Why Men and Class Matter. Cambridge, MA: Harvard University Press.

Winship, Christopher. 2009. "Time and Scheduling." Pp. 499-520 in Oxford Handbook of Analytical Sociology, edited by Peter Hedström and Peter Bearman. Oxford: Oxford University Press.

Young, Cristobal. 2012. "Losing a Job: The Non-pecuniary Cost of Unemployment in the United States." Social Forces 91:609-34. http://dx.doi.org/10.1093/sf/sos071

Zerubavel, Eviatar. 1981. Hidden Rhythms: Schedules and Calendars in Social Life. Berkeley: University of California Press.

Zerubavel, Eviatar. 1985. The Seven Day Circle: The History and Meaning of the Week. Chicago: University of Chicago Press.

Acknowledgements: The authors thank Tomás Jiménez, Corey Fields, Lindsay Owens, Ezra Zuckerman, Paul DiMaggio, Martin Ruef, Sara McLanahan, Suzanne Bianchi, Danny Schneider, Paolo Parigi, Patricia Young, and Sociological Science editor Stephen Morgan for valuable suggestions and constructive criticism. C.L. would like to thank Gallup for granting access to the Gallup Daily Poll data.

Cristobal Young: Department of Sociology, Stanford University. E-mail: cristobal.young@stanford.edu.

Chaeyoon Lim: Department of Sociology, University of Wisconsin-Madison. E-mail: clim@ssc.wisc.edu. 